\title{
PERSPECTIVISMO AMERÍNDIO COMO MODELO DE DESENVOLVIMENTO E SUSTENTABILIDADE: GIRO DESCOLONIZADOR SOBRE A NATUREZA
}

\author{
AMERINDIAN PERSPECTIVISM AS A MODEL OF DEVELOPMENT AND \\ SUSTAINABILITY: A DECOLONIZING GYRUS ON NATURE \\ PERSPECTIVISMO AMERINDIO COMO MODELO DE DESARROLLO Y
SOSTENIBILIDAD: GIRO DESCOLONIZADOR SOBRE LA NATURALEZA
}

Diógenes Alencar Bolwerk ${ }^{1}$

Marina Haizenreder Ertzogue ${ }^{2}$

\begin{abstract}
Resumo
Este artigo versa sobre o perspectivismo ameríndio como modelo de desenvolvimento e sustentabilidade, em oposição ao modelo capitalista ocidental entranhado nas estruturas socioprodutivas. A natureza é apresentada no espectro descolonizador que promove a reconexão do humano como estrutura integrada aos processos naturais. Portanto, pretende-se apresentar um contraponto entre o domínio cosmológico ocidental, que estabelece o padrão colonial-moderno-capitalista de poder sobre a natureza e o perspectivismo ameríndio, o qual pretende refundar o humano à natureza. A compreensão do domínio epistemológico ocidental permite comparar e deslocar os conceitos de precificação e de objetificação da natureza, para transvalorar a outra escala de desenvolvimento e sustentabilidade para uma ecologia pachamama. No aspecto metodológico, este estudo faz uma revisão bibliográfica e apresenta de forma interdisciplinar os textos de teóricos decoloniais, na maioria, latino-americanos, de grande visibilidade acadêmica. Destarte, o artigo indica que o modelo de desenvolvimento e sustentabilidade perpassa pela mudança de modelo societário fundado no multicultutralismo ocidental para a adoção da interculturalidade como exigência da capacidade de criar formas de compreensão, colaboração, reciprocidade e solidariedade, através de um novo paradigma societário.
\end{abstract}

Palavras-chave: Perspectivismo ameríndio. Descolonização da natureza. Cosmologia. Interdisciplinaridade. Interculturalidade.

\begin{abstract}
This article discusses Amerindian perspectivism as a model of development and sustainability, in opposition to the Western capitalist model embedded in the socio-productive structures. Nature is presented in the decolonizing spectrum that promotes the reconnection of the human as an integrated structure to natural processes. Therefore, it is intended to present a contraposition between the Western cosmological domain, which presents a colonialmodern-capitalist pattern of power over nature and the Amerindian perspectivism, that aims to deepen the human to nature. Understanding the Western epistemological domain allows a comparison between pricing and objectification of nature, and shifts their concept through pondering them to another scale of development and sustainability, such as the pachamama ecology. In the methodological aspect, a bibliographic review was carried out, and it was presented, in an interdisciplinary way, the writings of decolonial theorists, mostly latin americans, with high academic visibility. It is possible to assert along these lines, that the development and sustainability model involves a change in the corporate model based on western multiculturalism to adopt interculturality as a requirement for the ability to create new forms of understanding, collaboration, reciprocity and solidarity, through a new corporate paradigm.
\end{abstract}

Keywords: Amerindian perspectivism. Decolonization of nature. Cosmology. Interdisciplinarity. Interculturality.

\footnotetext{
${ }^{1}$ Mestrado em Geografia pela Universidade Federal do Tocantins, Brasil. Doutorando em Ciências do Ambiente pela Universidade Federal do Tocantins, Brasil. E-mail: diogenes.bolwerk@uft.edu.br.

${ }^{2}$ Doutorado em História Social pela Universidade de São Paulo. Professora Titular do Programa de Ciências do Ambiente da Universidade Federal do Tocantins, Brasil. E-mail: marina@uft.edu.br.
} 


\section{Resumen}

Este artículo trata sobre el perspectivismo amerindio como modelo de desarrollo y sostenibilidad, en oposición al modelo capitalista occidental enraizado en las estructuras socioproductivas. La naturaleza se presenta en el espectro descolonizador que plantea la reconexión de lo humano como estructura integrada a los procesos naturales. Por lo tanto, se pretende presentar una contraposición entre el dominio cosmológico occidental, que establece el marco colonial-moderno-capitalista de poder sobre la naturaleza y el perspectivismo amerindio, que pretende reconducir lo humano a la naturaleza. La comprensión del dominio epistemológico occidental permite comparar y alejar los conceptos de precificación y cosificación de la naturaleza, para revalorarla, en otra escala de desarrollo y sostenibilidad, en una ecología pachamana. Desde el punto de vista metodológico, este estudio hace una revisión bibliográfica y presenta de forma interdisciplinaria los textos de teóricos decoloniales, en su mayor parte latinoamericanos, de gran visibilidad académica. De esa manera, el artículo indica que el modelo de desarrollo y sostenibilidad implica el cambio del modelo societario fundado en el multiculturalismo occidental para la adopción de la interculturalidad como exigencia de capacidad para crear formas de comprensión, colaboración, reciprocidad y solidaridad, por medio de un nuevo paradigma societario.

Palabras-clave: Perspectivismo amerindio. Descolonización de la naturaleza. Cosmología. Interdisciplinariedad. Interculturalidad.

\section{Introdução}

O artigo é resultado de investigação bibliográfica e documental, fruto dos estudos acadêmicos desenvolvidos no doutoramento em Ciências do Ambiente na linha de pesquisa Natureza, cultura e sociedade, sob orientação e supervisão, bem como de estudos decoloniais apresentados no doutorado sanduíche na Universidade de Coimbra, complementares ao Programa de Pós-graduação em Ciências do Ambiente da Universidade Federal do Tocantins (PPGCiamb/UFT).

A delimitação do assunto procede de uma profícua discussão e constatação em seminários realizados na Universidade de Coimbra sobre a necessidade de descolonizar as estruturas de domínio submetidas à natureza, ou seja, pensar um modelo de desenvolvimento e sustentabilidade requer o questionamento do modelo e da cultura atual das sociedades ocidentais.

Para se chegar ao resultado deste documento, fez-se o esforço interdisciplinar que transcorre a crítica da visão produtivista da interdisciplinaridade, ou seja, a ideia parcial de que interdisciplinaridade é apenas a busca de ferramentas metodológicas. No entanto, procurou-se avançar no debate e entender que os aspectos interdisciplinares são exercícios de concitar outras formas de acessar o conhecimento, um trabalho necessário, pois, a interdisciplinaridade é a guisa de discussões das ciências do ambiente, porque natureza, cultura e sociedade são inseparáveis dentro de uma abordagem descolonizadora.

O objetivo é estabelecer critérios de investigação e de argumentação sobre modelo de desenvolvimento e sustentabilidade que descolonize a natureza, por se entender que o padrão ocidental do sistema-mundo atual é extremamente mercantilista e predatório à natureza. 
Portanto, partiu-se para o conceito do perspectivismo ameríndio inserido em uma cosmologia pachamama $^{3}$, que concilia os vários atores viventes e não viventes para integrar ao corpo sistêmico planetário unívoco.

Ressalte-se que o entendimento sobre desenvolvimento e sustentabilidade é o de trazer o social para a questão ambiental; de repensar o ser humano como componente da questão natural para uma ecologia da natureza, e assim diz respeito ao retorno de propostas de desenvolvimento e sustentabilidade que operam fora do espectro ocidental-capitalista, para suscitar e fomentar discussões científicas, sociais, culturais e ambientais na sociedade.

A justificativa vem da relevância de possibilitar outros debates sobre o tema desenvolvimento e sustentabilidade, analisado de maneira interdisciplinar, isto é, com o tecido social, composto por cada segmento da sociedade, considerado parte sui generis do processo, sem perder de vista a perspectiva ambiental como valoroso componente para se pensar estruturas humanas e não humanas, no complexo e diversificado mundo em que se vive.

Ao abordar a cosmologia ameríndia, estabeleceu-se ponto de reflexão, — o pensamento decolonial, através do qual se propôs discussão teórica, conceitual e alargada do debate para se avançar na área ambiental. Logo, percebeu-se a importância de progredir em uma questão interdisciplinar tão necessária e pertinente às Ciências do Ambiente para vislumbrar perspectivas epistemologias, propostas inovadoras de trabalho.

O contexto vivido pelas sociedades ocidentais, bem como os gargalos ambientais presentes, demonstra que o projeto político-social-econômico não consegue harmonizar-se com a sustentabilidade planetária, e seus desdobramentos implicam temas pertinentes para a compreensão da teia socioambiental. Ao se apresentar outra forma de organização societária estritamente ligada à natureza, torna-se bastante condizente e coerente com a atualidade, haja vista que o pensamento cosmológico ocidental demonstrou, até o momento, a incapacidade de arranjos que promovam desenvolvimento e sustentabilidade consistentes com as reais capacidades de recuperação e regeneração planetária.

\section{Metodologia}

A construção de uma abordagem considera o desenvolvimento da narrativa do artigo e do posicionamento diante de movimentos: político, social, crítico-reflexivo e científico. A metodologia proposta decorre da revisão bibliográfica de autores relacionados aos

\footnotetext{
${ }^{3}$ Pachamama é utilizado no contexto do artigo como Planeta Terra ou Mãe-Natureza.
} 
conhecimentos decoloniais, e preocupou-se em apresentar autores expoentes no âmbito da decolonialidade da natureza.

A preocupação com a interdisciplinaridade de saberes é recorrente na abordagem deste estudo, interessado em promover e envolver conceitos e linguagem que vislumbrem formas seguras para futuras pesquisas e entendimento da realidade. De acordo com Minayo et al. (2000, p. 25):

os procedimentos se realizam fundamentalmente por uma linguagem fundada em conceitos, proposições, métodos e técnicas, linguagem esta que se constrói com um ritmo particular e com olhar aguçado para os fenômenos apresentados pela realidade.

Desta forma, a particularidade da linguagem deste artigo é fundamentada em diálogos altamente interdisciplinares. O referencial teórico decolonial implica afirmar, e pretende descortinar, as narrativas ocidentais das não ocidentais, isto é, realizar uma revisão de conhecimentos por meio de uma decolonialidade da natureza.

\section{Perspectivismo ameríndio}

O perspectivismo ameríndio é compreendido como um conjunto de práticas e racionalidades denominadas cosmológicas dos povos originários da América do Sul, em particular os Yanomami e Andinos, que partilham um conjugado de ações. A cosmologia ameríndia ultrapassa a compreensão do ser humano deslocado, exterior aos demais seres viventes e não viventes. O entendimento desta cosmologia reside na forte relação de horizontalidade estabelecida pelos seres da natureza e que remete a profundos processos de interação e reciprocidade. Diferentemente, a cosmologia ocidental valoriza a verticalização nas interações dos seres, dentro de um sistema-mundo no qual a cultura é o grande diferenciador, classificador das estruturas simbólicas e materiais. A esse respeito, Mignolo (2017, p. 6-7) diz,

\footnotetext{
a "natureza" era, na cosmologia europeia cristã, algo para conhecer; entender a natureza era igual a entender o seu criador, Deus. Mas os aimarás e os quíchuas não tinham essa metafísica; por conseguinte, não havia conceito comparável ao conceito europeu de "natureza". Em vez disso, eles dependiam da pachamama, conceito que os cristãos ocidentais desconheciam.
}

Ao impor um conceito de natureza diferente, os europeus estabeleceram o padrão colonial de poder sobre a natureza. Esta, objetificada, outrora sacralizada pela edenização como lugar onde o criador fez as criaturas e ordenou o mundo. Com o advento da colonialidade/modernidade/capitalismo e a introdução da técnica-tecnologia, o processo passou 
pela "domesticação" que acentuou a assimetria, dicotomizou conceitos e ideias como divino e natural e caminhou para a separabilidade entre cultura humana e natureza selvagem. Sobre isto Mignolo (2017, p. 8) discute que a "colonialidade envolveu a natureza e os recursos naturais em um sistema complexo de cosmologia ocidental, estruturado teologicamente e secularmente". É bem verdade que o mesmo sistema colonial produziu também uma estrutura epistemológica de saber legitimadora dos usos e recursos da natureza nesta cosmologia.

Compreender o domínio da natureza a partir da epistemologia ocidental é fundamental para deslocarmos e transvalorarmos a outra escala de saber, - um saber da floresta, como afirmam Kopenawa e Albert (2015, p. 547) em A Queda do Céu - título inspirado por um mito sobre o cataclismo que acabou com a primeira humanidade e que, para os Yanomami, pode prefigurar "o destino de nosso mundo, invadido pelas emanações mortíferas dos minérios e combustíveis".

O perspectivismo ameríndio entende que existe uma ecologia da natureza em oposição à ecologia humana do ocidente que se assenhora da natureza. A condição ameríndia é reintegrar o ser humano à humanidade ampliada entre seres viventes e não viventes. Assenta-se nesta lógica o desenvolvimento e a sustentabilidade planetária pachamama. Compreender a natureza, fora do espectro colonial, é analisa-la além do complexo intersubjetivo do sistema-mundo ocidental (DUSSEL, 2016).

A ecologia da natureza permite o entendimento do perspectivismo ameríndio, ao lançar um olhar sobre a natureza descolonizada. Neste debate, a natureza ganha dimensão de humanidade que opera em todos os seres viventes. Desta forma, necessita-se de uma abordagem antropológica decolonial, como afirma Viveiros de Castro (2014, p. 40) “Anthropology is ready to fully assume its new mission of being the theory/practice of the permanent decolonization of thought". Viveiros de Castro (2014, p. 55) relata:

This double, materialist-speculative twist, applied to the usual psychological and positivist representation of animism, is what we called "perspectivism", by virtue of the analogies, as much constructed as observed, with the philosophical thesis associated with this term found in Leibniz, Nietzsche, Whitehead and Deleuze.

Certamente o realismo-especulativo que Viveiros de Castro apresenta tem fortes aproximações com as formas de subjetividades cosmológicas do perspectivismo ameríndio, como observa:

To this we added the synoptic concept of multinaturalism, which presented amerindian thought as an unsuspected partner, a dark precursor if you will, of certain contemporary philosophical programs, like those developing around theories of 
possible worlds, others that refuse to operate within the vicious dichotomies of modernity (VIVEIROS DE CASTRO, 2014, p. 49).

O realismo-especulativo é uma alternativa de alteridade com a vida, experiência de mundos possíveis que extrapolam o esquema colonial/moderno-ocidental e estabelece estreita correlação com o perspectivismo ameríndio. Além disso, é uma reflexão centrada na subjetividade cosmológica que estabelece um modo sui generis de interconexão planetária dos seres - uma perspectiva ampliada sobre o próprio conceito de humanidade.

O conceito mais alargado de seres que habitam o nosso dia a dia ou mesmo aqueles que coabitam, fazem-se presentes na realidade e são referências frequentes na concepção indígenaamazônica. No caso dos Yanomami, — os xapiri são espíritos que cantam e dançam, mas também são guardiões das florestas. Conforme Kopenawa e Albert (2015, p. 65) “Gostaria que os brancos parassem de pensar que nossa floresta é morta e que ela foi posta lá à toa. Quero fazê-los escutar a voz dos xapiri, que ali brincam sem parar, dançando sobre seus espelhos resplandecentes".

O desenvolvimento e a sustentabilidade defendidos por Kopenawa e Albert (2015) representam um ponto de vista, uma conduta, uma inflexão ao pensamento ocidental. Nesta perspectiva, precisamos decantar o conceito de natureza. Descolonizar a natureza é pensá-la para além de objeto mercantil; tê-la como ente vívido, — floresta que pulsa e resplandece em suas "veias" uma humanidade ampliada pelo espectro subjetivo do perspectivismo ameríndio e por uma ecologia da natureza, dando a possibilidade de resgatar o ser humano da ignorância e levá-lo ao equilíbrio cósmico.

O perspectivismo ameríndio desenvolve um conjunto de práticas acerca do multinaturalismo. Isto, em uma análise sinótica, é entender que essas subjetividades comportam um conjunto de pensamentos, crenças, ações, racionalidades e conceitos que, alinhavados em um sistema complexo de valores e atitudes, apresentam o multinaturalismo como conjunto de discussão filosófica. De acordo com Viveiros de Castro (2008, p. 33) “todo mundo é humano, apenas alguns desses humanos são menos humanos que os outros".

Nessa ótica, a generalidade à "substância em abundância", que compõe o universo, é a humanidade. Como diz Viveiros de Castro (2008, p. 94) “A humanidade é o fundo universal do cosmo. Tudo é humano.”. Entretanto, as subjetividades estão presentes, demarcadas pela condição biológica, nossa matriz animal. Isto é, diametralmente oposta ao pensamento ocidental.

Quando analisamos, sob a ótica da cosmologia ocidental, a diversidade apresenta-se na cultura e não no espectro animal, ou seja, a condição animal é válida a todos como generalizada; 
a especificidade dá-se no campo da cultura que é à base da diferenciação. Os humanos, portanto, são menos animais pela condição cultural inerente, intrínseca e mesmo exclusiva, pela capacidade unívoca de refletir sobre a sua existência, haja vista que o ser humano se diferencia, porque possui cultura.

No entanto, quando esse pensamento ocidental é confrontado com a cosmologia ameríndia, constata-se dessimetria, pois, na ótica ocidental "os humanos são animais que ganharam alguma coisa", para os ameríndios, "os animais são humanos que perderam alguma coisa" (VIVEIROS DE CASTRO, 2008, p. 94). Na cosmologia ameríndia, o humano é quem perdeu a capacidade de acessar um conceito ampliado de humanidade, ou seja, de enxergar a dos outros seres; desconectou-se dos espíritos intuitivos das florestas, quando se criou um conceito de humanidade desarraigado do mundo da vida.

É necessário observar outras faculdades dos sentidos e de compreensão do mundo: "la filosofía andina enfatiza las facultades no-visuales en su acercamiento a la realidade" (ESTERMANN, 2006, p. 113). Porque parte deste pensamento ameríndio/andino/amazônico abre várias possibilidades de compreensões de mundo e, como afirma Sousa Santos et al. (2009), é preciso apreender com as Epistemologias do Sul, é necessário acessar verdadeiramente as estruturas do outro.

\section{Interculturalidade como modelo de desenvolvimento e sustentabilidade}

A interculturalidade em nada diz respeito ao multiculturalismo criticado tão fortemente por Said (2011), posto que suas bases estão centradas na construção de estereótipos das cosmologias não eurocêntricas. Tampouco à produção de uma geografia do discurso que implica apequenar todas as narrativas explicativas de outros povos (MUDIMBE, 1988). A interculturalidade deve ser entendida como modelo de desenvolvimento e sustentabilidade planetário, que perpassa o mimetismo cultural, como faz o multiculturalismo liberal às outras culturas (BHABHA, 1998).

Desta forma, o interculturalismo permite discutir uma ecosofia (ESTERMANN, 2006). Isto é, elevar a discussão sobre a natureza a primeiro plano, em vez de secundário ou menor. A dificuldade de acessar a ecosofia, base da interculturalidade, está no fato de que esse pensamento opera outras grandezas e racionalidades que não fazem parte do escopo da biblioteca ocidental de compreensão do mundo.

No entanto, é necessário para salvaguardar a natureza, entender que se faz por ela, o eixo condutor dos saberes que reside neste pensamento. Obviamente, parece uma ideia 
transgressora, principalmente quando se parte da ótica do pensamento ocidental, tem-se relutância, bem como dificuldades de acessar facilmente esses conhecimentos.

Nesta perspectiva a natureza ganha função integradora, intercultural, condutora e fluída da própria vida, restabelecida como agente planetário de sustentabilidade entre os demais seres, de maneira que o desenvolvimento não se traduza em números ou monetarização, mas em formas de agenciamento dos habitantes do planeta, levados a considerar a reciprocidade e a capacidade de interconexão dos seres viventes e não viventes e como podem contribuir para manter o equilíbrio planetário. Este conjunto articulado de ideias se chama ecosofia, expressada na interculturalidade ameríndia.

Encontra-se um pensamento similar na perspectiva ameríndia andina: "la 'naturaleza' es el todo de la 'realidad', y no una entidad opuesta a otra (como 'culturalidad' o 'espiritualidad')" (ESTERMANN, 2006, p. 191). Os povos andinos também trabalham em uma cosmologia, na qual a natureza não é só parte da realidade física, mas também compõe o imaterial, a espiritualidade. Isto é, não se pode pensar em uma visão fora da natureza, ambos andinos e Yanomami, o substrato comum é a humanidade inerente a todos os seres. Assim, tudo e todos compõem a natureza dentro da interculturalidade.

\section{Simetria generalizada como ruptura na construção da interculturalidade}

Sobre a problemática imposta pelas assimetrias cosmológicas, e na construção do debate para um desenvolvimento e sustentabilidade, Latour (2004) apresenta o que denominou de simetria generalizada, isto é, a reciprocidade de agenciamento, no qual estabelece o que classifica de rede-de-atores sobre o debate e os limites entre sujeito-objeto, cultura-natureza, humano-não-humano e sistema de produção-recurso natural. Latour (2004, p. 13-14) apresenta acerca do debate:

\footnotetext{
Muito longe de "ultrapassar" as dicotomias do homem e da natureza, do sujeito e do objeto, dos sistemas de produção e do ambiente, a fim de encontrar o mais rapidamente possível os remédios para a crise, era preciso, ao contrário, diminuir o movimento, tomar seu tempo, suspendê-lo, depois descer abaixo destas dicotomias para cavar como a velha toupeira.
}

O enfrentamento da questão homem e natureza levou Latour (2004) a discutir o que chamou de simetria generalizada de parâmetros, ou seja, analisar de forma equânime o cultural e o natural. Ao propor uma análise de reciprocidade de agenciamento tanto do social/cultural quanto do natural, coloca em evidência a fragilidade da visão humanista eurocêntrica. 
Assim, como o perspectivismo ameríndio defende a subversão do conceito de humanidade, ao dilata-la e ampliar a outra possibilidade, Latour (2004) também procura fazer o mesmo ao alargar o sentido do que entende por atores, ao oferecer "aos atores versões múltiplas e rapidamente revistas, que nos permitam compreender a experiência coletiva para a qual somos todos arrastados" (LATOUR, 2004, p. 365).

A simetria generalizada permite quebrar a compreensão verticalizada da natureza como objeto, de maneira que se avance na construção da interculturalidade para possibilitar um diálogo mais horizontal e níveis de aceitação que perpassam a apreensão de outra realidade, inclusive da forma como nos relacionamos e interagimos com a natureza. No entanto, Walsh (2008, p. 140) adverte sobre as genealogias das terminologias para ter a clareza do que se pretende abordar:

De hecho, los términos multi, pluri e interculturalidad tienen genealogías y significados diferentes. Lo pluricultural y multicultural son términos descriptivos que sirven para caracterizar la situación diversa e indicar la existencia de múltiples culturas en un determinado lugar planteando así su reconocimiento, tolerancia y respeto. El «multi» tiene sus raíces en países occidentales, en un relativismo cultural que obvia la dimensión relacional y oculta la permanencia de desigualdades e inequidades sociales.

Walsh (2008) reforça a ideia apresentada por Mudimbe (1988), Bhabha (1998) e Said (2011), de que o multiculturalismo é um projeto hegemônico que relativiza o outro, produz um modelo de desenvolvimento e sustentabilidade pautado na cultura do consumo e objetificação da natureza. Apesar de o multiculturalismo apregoar o respeito à diversidade, suas bases se assentam em arquétipos cujo ponto de partida inferioriza a cultura do outro.

Contudo, para Walsh (2008), o interculturalismo é um processo maior em fase de construção para um modelo societário pautado na reciprocidade, visto que a mudança é muito mais radical, para não dizer um completo rompimento com o sistema-mundo atual e a consecução de um novo-sistema. Inclusive, o estabelecimento de outros fundamentos organizativos e colaborativos para se encontrar formas de (re)conectar à mãe-natureza e suas dinâmicas.

O projeto da interculturalidade é algo do devir, do construir, mas para tanto é necessário reposicionar, inverter a lógica do padrão unitário de Estado para um modelo intercultural societário relacional, norteado pela reciprocidade. A interculturalidade é um caminho a ser pavimentado, que busca não apenas no nível sistêmico e institucional das garantias de um Estado-plurinacional, mas exige a capacidade de criar formas inovadoras de compreensão, convivência, colaboração, solidariedade, e assume como um conjunto de relações construídas, 
Perspectivismo ameríndio como modelo de desenvolvimento e sustentabilidade: giro descolonizador sobre a natureza

calcadas em processos conjunturais e estruturais que integram as diversas matrizes, agregando desta forma os elementos indígenas, africanos e europeus, bem como de outros grupos em um modelo societário plural, o qual reverbere para modelos de desenvolvimentos descolonizados.

Desta forma, a interculturalidade promove o entendimento da ideia do ator-rede e do agenciamento de humanos e não humanos, porque nesta concepção os atores não humanos não são estruturas inertes, mas relacionais, como bem aponta Tarde (2011), e abre a discussão para um diálogo no qual o mundo social também é povoado por atores não humanos, para romper com a visão eminentemente humana e propor uma nova compreensão do social. Diz Tarde (2011, p. 94):

Sólo hay un fin en la Naturaleza, un fin respecto del cual todo lo restante es medio; hay multitud de fines que buscan utilizarse mutuamente. Cada organismo, y en cada organismo cada cèlula, y en cada cèlula, quizá, cada elemento celular, tiene su pequenã providencia á si y en sí.

Quando os atores não humanos, neste caso específico, a natureza é observada fora da simples condição de objeto e da lógica da mercantilização, mas percebida como complexidade tecida de processos e interações que envolvem seres vivos (humanos e não humanos) e não viventes (minerais, artefatos, tecnologias etc.). Estes formam, por assim dizer, as redes-deatores, dotadas de significados cujo papel é realizar intervenções. Eles estão nas estruturas e interagem com os humanos.

Quando se discute a viabilidade de descolonizar o olhar sobre a natureza, de vê-la como agente dotado de expressão, temporalidade, espacialidade e formas de atuação, ou seja, autônoma na existência; como diria Engels (1978), há uma dialética da natureza que é separável da dialética humana.

A separação dos humanos e não humanos é um produto da constituição do pensamento ocidental que atende fortemente "No que diz respeito ao relativismo cultural, mais sutil, a natureza entra em cena, mas para existir ela não supõe nenhuma sociedade, nenhuma construção, nenhuma mobilização, nenhuma rede" (LATOUR, 1994, p. 102).

Assim, expõe as diferenças de constituições entre sociedades fundadas nos princípios da modernidade ocidental e as sociedades não ocidentais, como é o caso das ameríndias e seus processos cosmológicos de profunda relação entre o ser humano e a natureza. Para Latour (1994), o relativismo cultural também não consegue enfrentar os complexos entendimentos entre as dimensões da natureza e do ser humano. Por mais que o relativismo cultural busque romper com a visão etnocêntrica e valorize a experiência das diferentes culturas como ponto de 
argumentação inicial, não consegue atacar o foco primordial, ou seja, observar a base comum entre natureza e humanidade, bem como sua filiação à mesma matriz planetária.

Desta forma, a simetria generalizada não nega as diferenças ou assimetrias culturais, os aspectos constitutivos dos humanos e não humanos, mas coloca em questão a possibilidade de se pensar as assimetrias pelo viés de equidade de valores, sem anular as diferenças estéticas ou éticas, mas para valorar equitativamente às fundamentações conceituais de cada constituição cultural. Os parâmetros descolonizadores da natureza são norteadores da reciprocidade e sustentabilidade na conquista de espectro societário intercultural.

\section{Considerações finais}

No sistema-mundo ocidental, as forças produtivas demonstram que o modelo de desenvolvimento planetário opera no espectro capitalista, que em seu conjunto de regras estabelece o entendimento do que venha a ser sustentabilidade a partir da cosmologia ocidental. Em síntese, opera sobre separabilidade da condição humana como corpo desconexo da própria natureza.

A compreensão do domínio epistemológico ameríndio permite comparar e vislumbrar outra escala de desenvolvimento e sustentabilidade, direcionada a uma ecologia da natureza como modelo de sustentabilidade planetária. Tal proposta requer romper com a estrutura capitalista atual, bem como repensar a alteridade com a vida planetária, e, por assim dizer, interconectar através de uma humanidade mais alargada.

Isto posto, é imperioso o exercício de descolonizar as ações e fazê-lo permanentemente, para o exercício intelectual de compreensão e acesso à cosmologia ameríndia, e assim partir do entendimento de que é valioso buscar em um novo-mundo descolonizado os ingredientes que interroguem e suplantem as estruturas do sistema-mundo atual, fundado na cosmologia ocidental.

Alerta-se para a necessidade de compreender que o multiculturalismo não consegue abarcar a complexidade e as conexões de conceitos em diálogo entre humanos e não humanos, viventes e não viventes, posto que ainda opera no campo de dicotomias que estabelecem um conjunto de regras de separabilidade entre cultura e natureza.

$\mathrm{Na}$ interculturalidade, o modelo de desenvolvimento e sustentabilidade transcorre para adoção do padrão societário fundado em uma relação frágil e instável, que transita entre equilíbrio e desequilíbrio. Assim, o que determina a variação de estados e a manutenção do equilíbrio é o grau de responsabilidade mantido por cada ente em relação ao todo, enquanto 
compromisso consciente com o planeta. Então, a interculturalidade convoca a todos para pactuar e criar as capacidades de compreensão, colaboração, reciprocidade, agenciamento e solidariedade, através de um novo paradigma social e planetário de desenvolvimento e sustentabilidade.

Por fim, a cosmologia ameríndia tem muito a ensinar enquanto projeto de desenvolvimento e sustentabilidade planetária, seus fundamentos defendem relações horizontais nas quais todos são seres da natureza, seres sagrados. Nesta perspectiva, a horizontalidade é interativa, o agenciamento é integrador e todos se interligam com o cosmo, no qual tudo está relacionado em uma teia socioambiental.

\section{REFERÊNCIAS}

BHABHA, Homi K. O local da cultura. 1. ed. Belo Horizonte: Editora UFMG, 1998.

DUSSEL, Enrique. Transmodernidade e interculturalidade: interpretação a partir da filosofia da libertação. Revista Sociedade e Estado, Brasília, v. 31, n. 1, p. 51-73, 2016. DOI: https://doi.org/10.1590/S0102-69922016000100004.

ENGELS, Friedrich. A dialética da natureza. 3. ed. Rio de Janeiro: Civilização Brasileira, 1978.

ESTERMANN, Josef. Filosofía andina: sabiduría indígena para un mundo nuevo. 2. ed. La Paz: ISEAT, 2006.

KOPENAWA, Davi; ALBERT, Bruce. A queda do céu: palavras de um xamã yanomami. 1. ed. São Paulo: Companhia das Letras, 2015.

LATOUR, Bruno. Jamais fomos modernos: ensaio de Antropologia simétrica. 1. ed. Rio de Janeiro: Editora 34, 1994.

LATOUR, Bruno. Políticas da natureza: como fazer ciência na democracia. 2. ed. Bauru: EDUSC, 2004.

MIGNOLO, Walter D. Colonialidade: o lado mais escuro da modernidade. Revista Brasileira de Ciências Sociais, São Paulo, v. 32, n. 94, p. 1-18, 2017. DOI: http://dx.doi.org/10.17666/329402/2017.

MINAYO, Maria Cecília de Souza et al. (orgs.). Pesquisa social: teoria, método e criatividade. 17. ed. Petrópolis: Vozes, 2000.

MUDIMBE, Valentin-Yves. The invention of Africa: gnosis, philosophy and the order of knowledge. 1. ed. Bloomington: Indiana University Press, 1988.

SAID, Edward W. Cultura e imperialismo. 9. ed. São Paulo: Companhia das Letras, 2011. 
SOUSA SANTOS, Boaventura de; MENESES, Maria Paula (org.). Epistemologias do Sul. 4. ed. Coimbra: Edições Almedina S.A., 2009.

SZTUTMAN, Renato (org.). Eduardo Viveiros de Castro. 1. ed. Rio de Janeiro: Beco do Azougue, 2008. (Encontros).

TARDE, Gabriel. Las leyes sociales. Athenea Digital, Barcelona, v. 11, n. 1, p. 255-272, 2011. DOI: https://doi.org/10.5565/rev/athenead/v11n1.848.

VIVEIROS DE CASTRO, Eduardo. Cannibal metaphysics: for a post-structural Anthropology. 1. ed. Minneapolis: Univocal Publishing, 2014.

VIVEIROS DE CASTRO, Eduardo. Orientalismo: o Oriente como invenção do Ocidente. 1. ed. São Paulo: Companhia das Letras, 1990.

VIVEIROS DE CASTRO, Eduardo. Xamanismo transversal: Lévi-Strauss e a cosmopolítica amazônica. In: QUEIROZ, R. de C.; NOBRE, R. F. (org.). Lévi-Strauss: leituras brasileiras. Belo Horizonte: Editora UFMG, 2008. p. 79-124.

WALSH, Catherine. Interculturalidad, plurinacionalidad y decolonialidad: las insurgencias político-epistémicas de refundar el Estado. Tabula Rasa, Bogotá, v. 6, n. 9, p. 131-152, 2008. DOI: https://doi.org/10.25058/issn.2011-2742. 